\title{
Kreativitas Guru TKIT Al Mishbah Dalam Pengembangan Model Pembelajaran Lab Mini Melalui Terrarium Ekosistem
}

\author{
Fatikhatun Nikmatus Sholihah ${ }^{1}$ \\ Universitas KH A. Wahab Hasbullah, fatiha.achmad@unwaha.ac.id \\ Anggun Wulandari² \\ Universitas KH A. Wahab Hasbullah, anggun.4w@gmail.com \\ Umi Kulsum Nur Qomariyah ${ }^{3}$ \\ Universitas KH A. Wahab Hasbullah, umiqomariah@gmail.com
}

\begin{abstract}
Abstrak
Pembelajaran di sentra alam dengan tema lingkungan alam memiliki tantangan tersendiri bagi guru-guru dalam pelaksanaanya dikarenakan lahan yang sedikit. Guru masih banyak menggunakan lembar kerja siswa yang dibeli dari toko-toko buku dan kurang kreatif sehingga tidak mengembangkan media sendiri. Maka dibutuhkan pelatihan pembuatan media yang dapat menggambarkan situasi ekosistem yaitu terrarium ekosistem. Terrarium merupakan media yang terbuat dari kaca baik botol, aquarium atau plastik transparan yang berisi tanaman dengan metode yang unik yang disesuaikan dengan kondisi alam yang sesungguhnya. Pengabdian ini bertujuan untuk memberikan pelatihan bagi guru TKIT Al Mishbah menciptakan eksosistem mini dalam suatu media kaca agar mempermudah guru dalam mengajarkan Lingkungn Alam yang disebut terrarium. Pelaksanaan kegiatan berlangsung selama 4 hari mulai 25 juni sampai 28 juni 2019. Metode pelaksanan kegiatan ini dilakukan dengan cara tutorial terbimbing. Pembuatan terrarium meliputi pembuatan terrarium ekosistem gurun, terrarium hutan hujan tropis, dan terrarium savana. Hasil dari pelatihan ini adalah pelatihan terrarium ekosistem sebagai media pembelajaran Lab Mini dapat meningkatkan pemahaman guru tentang pengembangan pembelajaran Lab Mini di TK dan melalui pelatihan ini dapat meningkatkan kreativitas guru dalam membuat media pembelajaran lab mini berupa terrarium ekosistem.. Kegiatan pengabdian masyarakat ini menjadi solusi permasalahan yang dihadapi oleh guru dalam materi ekosistem di sekolah, sehingga guru dapat menyeimbangkan antara teori dengan kondisi alam sesungguhnya.
\end{abstract}

Kata Kunci: Terrarium, Guru TKIT Al Mishbah, Lab Mini.

\begin{abstract}
Learning in the natural center study with the theme of natural environment has its own challenges for teachers in its implementation due to the small amount of land. Many teachers still use student worksheets purchased from bookstores and are less creative so they do not develop their own media. So it takes training in making media that can describe the situation of the ecosystem. It is called terrarium ecosystem. Terrarium is a medium made of glass, both bottles, aquariums or transparent plastic containing plants with unique methods that are adapted to the real natural conditions. This service aims to provide training for TKIT teachers Al Mishbah to create mini-ecosystems in a glass media to facilitate teachers in teaching the Natural Environment Terrarium.. The activity takes place for 4 days starting June 25 to June
\end{abstract}




\section{JURNAL ABDIMAS BSI}

Jurnal Pengabdian Kepada Masyarakat

28 2019. The method of implementing this activity is carried out by means of a guided tutorial. Making terrariums includes making desert terrarium ecosystems, terrariums of tropical rainforests, and terrarium savannahs. The results of this training are terrarium ecosystem training as a Mini Lab learning media can improve teacher understanding of the development of Mini Lab learning in kindergarten, ecosystem terrarium training as a Mini Lab learning media can increase teacher creativity in making mini lab learning media in the form of ecosystem terrarium. This is the solution to the problems faced by teachers in the ecosystem material in schools, so that teachers can balance the theory with the real natural conditions.

\section{Keywords: Terrarium, TKIT Al Mishbah' Teacher, Mini Lab}

\section{Pendahuluan}

TKIT Al Misbah adalah Taman Kanak Islam Terpadu yang mempunyai 4 sentra yaitu sentra bahan alam, sentra balok, sentra main peran, dan sentra persiapan. Di ruangan sentra alam siswa TK diajari lebih mengenal tentang alam beserta interaksinya. Pengenalan tentang berbagai macam tanaman toga, menghitung jumlah dan mengenal bagian bagian ikan, percobaan gunung meletus, pembuatan telur asin, dan cooking class dengan mengolah bahan-bahan alami seperti buah-buahan. Kegiatankegiatan tersebut sangat berpengaruh terhadap afektif mereka terhadap lingkungan sekitar. Namun disayangkan, dalam tema Lingkungan Alam yang dilakukan selama 2 minggu tidak menunjukkan pembelajaran tentang interaksi makhluk hidup dengan lingkungan secara langsung. Menurut survey yang telah dilakukan, penyebab anakanak tidak bisa mengamati ekosistem secara langsung disebabkan lahan yang kurang maksimal yaitu tanaman di depan sekolah dan hanya melalui gambar. Selain itu, kegiatan mengamati alam lebih aman jika dilakukan didalam kelas karena letak sekolah dekat dengan jalan raya. Oleh sebab itu, sebagian besar kegiatan alam dilakukan di ruang sentra alam.

Hubungan interaksi terhadap lingkungan disebut dengan ekosistem. Komponen dalam ekosistem terdiri komponen biotik dan abiotik. Komponen biotik terdiri dari tumbuhan dan hewan sedangkan komponen abiotik terdiri dari batu, udara, air, dan tanah. Komponen biotik dalam ekosistem jika dilihat dari struktur trofiknya terdiri dari beberapa strata yaitu produsen, konsumen, dan pengurai. Komponen biotik di sekolah TKIT al Misbah berupa tanaman. Menurut definisi dan komponen ekosistem yang telah dijelaskan, ,maka di TKIT al mishbah dianggap kurang memenuhi dalam mengajarkan ekosistem. Oleh sebab itu, dibuatlah pelatihan dan workshop tentang media pembelajaran sains berbasis lab mini berupa tirrarium ekosistem.

Lab mini didasarkan pada kesederhanaan alat (benda-benda konkrit) yang digunakan dalam proses pembelajaran. Lab mini adalah kegiatan pengamatan dan percobaan yang dapat dilaksanakan baik di dalam laboratorium, di kelas maupun di lapangan dengan menggunakan benda-benda konkrit dan sederhana. Biggs, et al (2004) menyatakan lab mini hanya memerlukan waktu singkat untuk menemukan jawaban. Pembelajaran dengan menggunakan lab mini bisa dilakukan sendiri atau dengan bantuan guru. Dalam hal ini, penggunaan lab mini menggunakan bantuan dari guru karena jenjang sekolah masih TK. Pembelajaran lab mini bisa berhasil jika guru menguasai konsep lab mini melalui pembuatan media pembelajaran sendiri. Lucy 
(dalam Saragih, 2000) mengemukakan bahwa keunggulan lab mini diantaranya adalah dengan peralatan minimum: 1) siswa dapat melakukan kegiatan pengamatan, 2) untuk mempermudah siswa dalam memahami materi pelajaran karena siswa dihadapkan pada obyek langsung, 3) dapat membimbing siswa untuk menemukan sendiri, 4) melatih siswa untuk berpikir kritis, 5) melatih siswa untuk bertanya sehingga siswa lebih aktif, 6) mendorong siswa menemukan konsep-konsep baru, dan 7) memberikan kesempatan siswa untuk belajar dengan menggunakan metode ilmiah. Menyimak salah satu hakekat pembelajaran tentang alam adalah mendayagunakan kondisi alam di lingkungan siswa, semestinya pembelajaran alam beserta interaksinya (ekosistem) dapat dilakukan dengan menggunakan lab mini sekalipun dibatasi oleh waktu yang singkat.

Ada beberapa penelitian relevan yang mendukung penelitian ini. Hasil penelitian Dewi (1999) tentang penerapan metode pembelajaran kooperatif dengan menggunakaan lab mini menunjukkan bahwa $93,75 \%$ siswa mempunyai motivasi positif. Begitu juga penelitian Prayitno (2009) yang menyatakan bahwa pembelajaran lab mini lebih efektif dan lebih baik dari pada pembelajaran konvensional, dibuktikan dengan ketuntasan belajar secara klasikal sebesar 97,5\%. Kedua pernyataan tersebut didukung juga oleh Rusmiyati (1998), menyatakan bahwa penelitian Lab Mini dalam praktikum biologi dapat meningkatkan kualitas belajar siswa. Ketiga hasil penelitian tersebut, didasari oleh ungkapan Slavin (2006) bahwa dari pemikiran belajar kooperatif, siswa belajar dalam kelompok kecil yang bersifat heterogen dari segi gender, etnis, dan kemampuan akademik untuk saling membantu satu sama lain dalam mencapai tujuan bersama.

Mitra dalam kegiatan ini adalah guru-guru TKIT Al Mibah Dsn.Sedamar, Ds. Talun Kidul, Sumobito. yang berjumlah 15 orang. Sebagian besar, mereka berpendidikan S1 non PAUD dan Kebidanan. Artinya, guru-guru tersebut kurang memiliki potensi untuk melaksanakan tugasnya secara profesional. Selama ini organisasi profesi belum berfungsi dengan baik, sehingga profesionalitas guru belum berkembang dengan baik. Dalam melaksanakan tugas mendidik masih dengan pendekatan konvensional, termasuk dalam pengembangan sains. Guru masih banyak menggunakan lembar kerja siswa yang dibeli dari toko-toko buku, guru kurang kreatif sehingga tidak mengembangkan media sendiri, dan arah pembelajaran sains masih pada ranah kognitif. Hal ini menunjukkan masih perlu ditingkatkan mutu layanan pendidikan di taman kanak-kanak. Tujuan pengabdian ini adalah Memberikan pengetahuan teoritis kepada guru-guru tentang pembelajaran sains di TK melalui pelatihan dan melatih guru-guru TKIT Al Misbah membuat terrarium ekosistem sebagai alternative media pembelajaran untuk pengembangan sains anak TK berbasis Lab Mini. Manfaat pengabdian ini adalah pemahaman guru tentang pengembangan pembelajaran sains di TK dapat meningkatkan dan meningkatkan keterampilan guru dalam membuat media pembelajaran lab mini berupa terrarium ekosistem.

\section{Metode Pelaksanaan}

Metode pelaksanaan meliputi pelatihan dan workshop yaitu berupa pelatihan kepada mitra guru TKIT AL Mishbah. Produk yang akan dihasilkan berupa produk terrarium ekosistem (ekosistem gurun, ekosistem hutan hujan tropis, ekosistem savana). 
Metode pelaksanaan kegiatan pelatihan pembuatan terrarium dan produk tambahan lainnya melalui tutorial terbimbing. Kegiatan pelatihan melalui tahap-tahap berikut :

a. Analisis kebutuhan media pembelajaran guru dalam tema "Lingkungan Alam"

b. Menyusun dan menyediakan bahan-bahan yang digunakan dalam pembuatan terrarium

c. Menjelaskan mengenai alat dan bahan yang digunakan dalam pembuatan terrarium.

d. Instruktur menjelaskan fungsi masing-masing alat dan bahan.

e. Instruktur mendemonstrasikan cara pembuatan terrarium sesuai dengan prosedur cara kerja pembuatan terrarium.

f. Peserta diberi kesempatan untuk melakukan prosedur pembuatan terrarium secara mandiri.

g. Instruktur mengamati dan membantu perserta secara terbimbing.

h. Evaluasi kegiatan akhir, kendala yang menyulitkan guru dalam pembuatan terrarium.

i. Setelah kegiatan ini berakhir, guru akan diberikan sertifikat telah mengikuti Pelatihan Pembuatan Terrarium Ekosistem Sebagai Media Pembelajaran Lab Mini

\section{Hasil dan Pembahasan}

Ada dua tahap dalam pelatihan ini yaitu tahap persiapan sebelum pelatihan dan tahap pelaksanaan

1. Tahap Persiapan

Pada tahap kegiatan pengabdian masyarakat dilakukan terlebih dahulu persiapan dengan melakukan kegiatan pengumpulan data pendukung seperti menyiapkan bahan dan alat, serta pembelian bahan dan alat untuk pelatihan pembuatan terrarium yang dilaksanankan tanggal 25-28 Juni 2019. Bahan - bahan dan alat-alat terrarium meliputi aquarium kaca bulat berukuran 3,5 L, sphagnum moss, batuan zeolit, kerikil aneka warna, arang, tanah kompos, pasir halus, corong, sekop mini, pinset , kain lap, gunting, cutter, ,ember kecil (baskom), glass ware (bejana tempat tirarium), tanaman succulen, kaktus, bunga ekor tupai, bunga kriptantus.

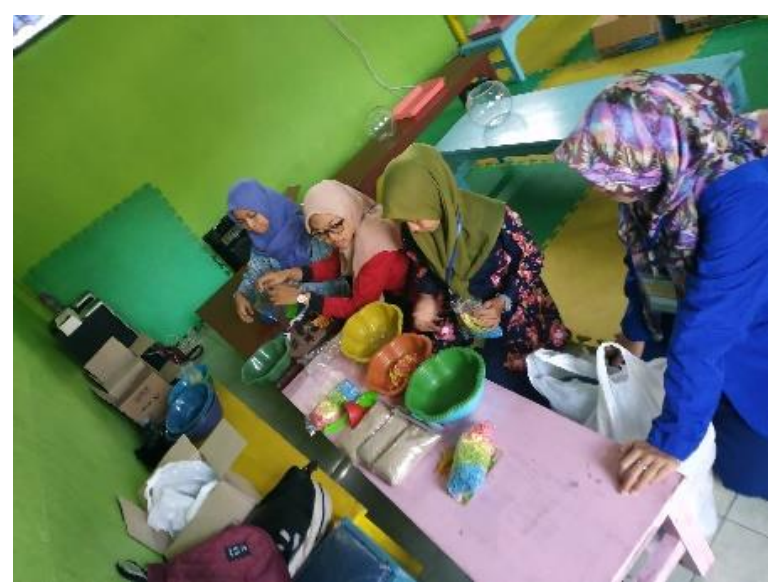

Gambar 1. Persiapan Pembuatan Terrarium 


\section{JURNAL ABDIMAS BSI}

Jurnal Pengabdian Kepada Masyarakat

2. Tahap Pelaksanaan

Pelatihan terrarium ini dilaksanakan dengan baik dan sukses. Kegiatan ini diawali dengan penjelasan tentang media pembelajaran lab mini dan terrarium (materi pertama), botani untuk terrarium (materi kedua), dan ekosistem (materi ketiga). Ketiga materi tersebut untuk menggambarkan ekosistem yang ada dan menambah kretifitas guru dalam membuat media pembelajaran.

Pembuatan terrarium yang diawali dengan tutorial dari instruktur dilakukan pada hari kedua. Kemudian dilanjutkan oleh peserta pelatihan secara mandiri dengan arahan instruktur. Pembuatan terrarium dibagi menjadi 3 tema yaitu ekosistem gurun, ekosistem hutan hujan tropis, dan ekosistem savana. Ekosistem gurun dilakukan pada hari kedua pelatihan. Ekosistem hutan hujan tropis dan savana pada hari ketiga pelatihan. Berikut adalah gambar ketika instruktur melakukan tutorial pembuatan terraium.

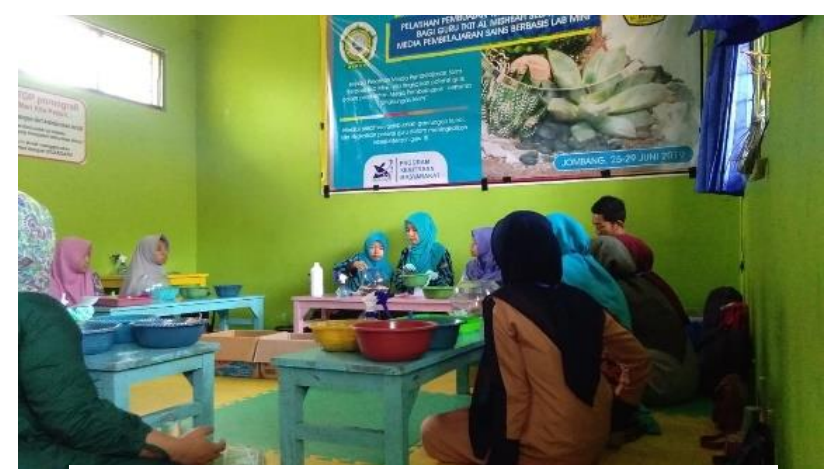

Gambar 2. Tutorial Pembuatan Terrarium

Para peserta dibagi atas 5 tim. Masing masing tim terdiri dari 3 orang. Namun seluruh jumlah peserta melebihi 15 orang dengan orang yang berbeda tiap harinya. Total jumlah peserta 19 orang. Peserta dilatih bagaimana membedakan tehnik pembuatan terrarium padang pasir, terrarium hutan hujan tropis, dan terrarium savana.

Pada tahap pembuatan terrarium harus sesuai dengan tahap-tahapnya.

1. Sebelum membuat terrarium, aquarum disemprot/dilap dengan alkohol. Hal ini bertujuan untuk mensterilkan aquarium dari bakteri/jamur yang mengganggu pertumbuhan tanaman.

2. Pada pembuatan terrarium gurun, bagian dasar aquarium diletakkan batu-batu kerikil kemudian spagnum moss yang berfungsi sebagai dasar media tanam dan sebagai penyerap air. Kemudian arang yang berguna untuk menyerap racun yang terdapat pada akar tanaman.

3. Setelah diletakkan kerikil, spagnum moss, dan arang pada dasar aquarium maka tahap selanjutnya adalah meletakkan tanah kompos kemudian pasir pada bagian atas. Tanaman ditanam setelah meletakkan tanah kompos. Pembuatan 


\section{JURNAL ABDIMAS BSI}

Jurnal Pengabdian Kepada Masyarakat

terrarium gurun diakhiri dengan melatakkan miniatur hewan sesuai ekosistem dan kerikil warna.

4. Pada terrarium ekosistem hutan hujan tropis, terdapat perbedaan dimana setelah batu kerikil maka tahap selanjutnya adalah pasir kemudian tanah kompos di atas permukaannya. Tanaman ditanam setelah tanah kompos, diakhiri dengan lumut atau rumput jepang. Miniatur hewan sesuai dengan ekosistem juga dilakukan.

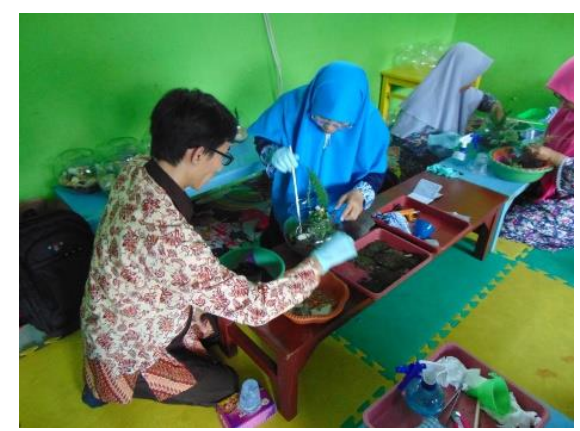

Gambar 3. Kegiatan Pembuatan Terrarium oleh Peserta

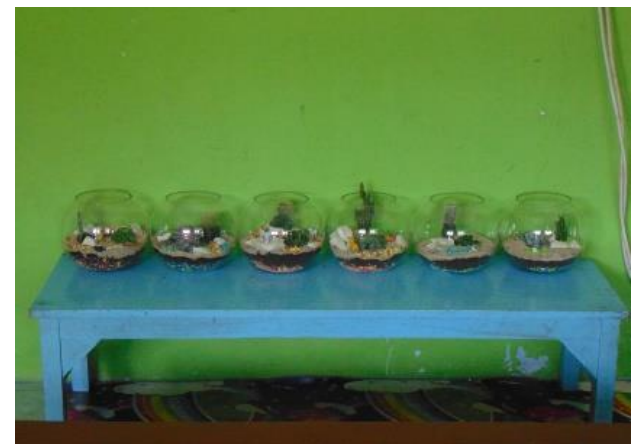

Gambar 4. Hasil Terrarium Gurun Oleh Peserta

Akhir tahap pelaksanaan, panitia melakukan foto bersama peserta dan serah terima sebagian produk kepada pihak sekolah.

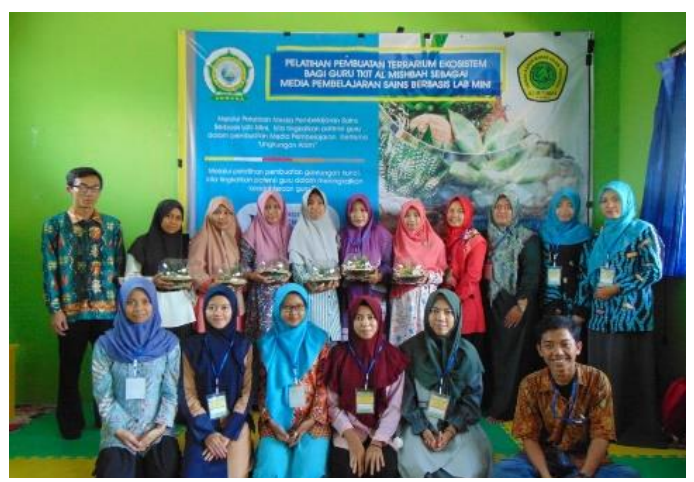

Gambar 5. Panitia beserta Peserta dengan Hasil Karyanya. 
Jurnal Pengabdian Kepada Masyarakat

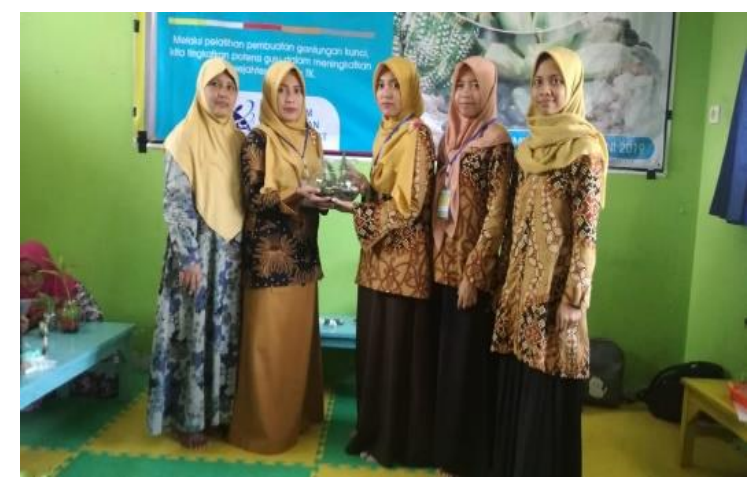

Gambar 6. Serah Terima Produk kepada Pihak Sekolah

Peningkatan keterampilan guru dalam membuat media pembelajaran lab mini berupa terrarium ekosistem diperoleh dari angket ketarampilan guru yang diberikan sebelum acara serah terima produk. Adapun hasil respon peningkatan keterampilan guru dapat dilihat pada Gambar 7.

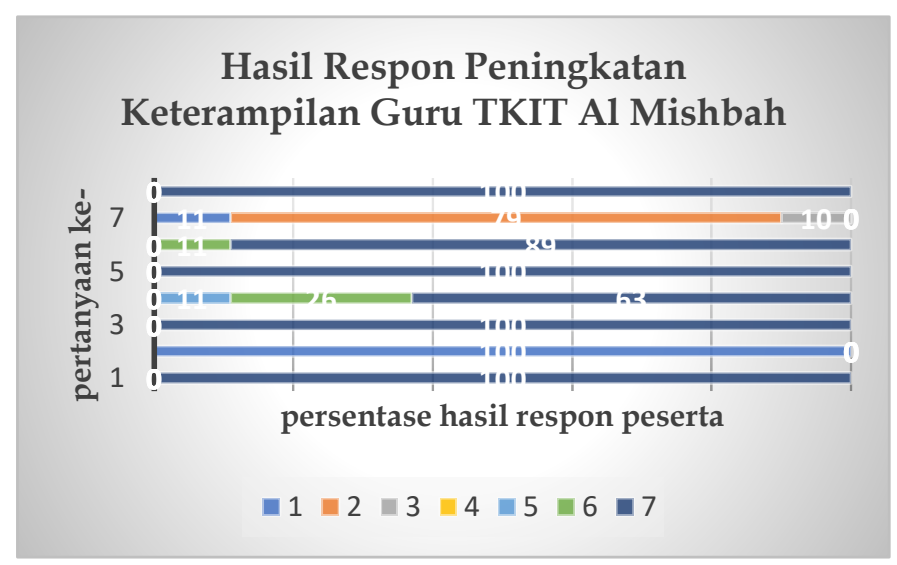

Gambar 7. Grafik Hasil Respon Peningkatan Keterampilan Guru TKIT Al Mishbah

Berdasarkan hasil grafik di atas, dapat dilihat bahwa $100 \%$ peserta pernah menggunakan media pembelajaran, peserta merasa pelatihan pembuatan terrarium menambah keterampilan dan wawasan untuk memperkaya variasi media pembelajaran sains, serta pelatihan pembuatan terrarium sebagai media pembelajaran sains bermanfaat bagi peserta. Selain itu, 100\% peserta belum pernah menggunakan terrarium sebagai media pembelajaran.

$63 \%$ peserta merasa mudah dalam pembuatan terrarium dan $89 \%$ akan membuat sendiri terrarium tersebut, namun $79 \%$ tidak ingin mengarahkan peserta didik membuat terrarium. Hal ini disebabkan rentang usia peserta didik antara 5-7 tahun, sehingga peserta beranggapan bahwa masih terlalu dini mengajarkan kepada anak usia dini. Secara keseluruhan keterampilan guru meningkat karena rasa ingin tahu peserta tentang terrarium. Hal tersebut senada dengan pendapat Kemp (1994) bahwa keinginan mau belajar akan timbul apabila proses pembelajaran dipersiapkan dengan 
baik sehingga dirasakan penting dan menarik, tersedia sebagai pengalaman belajar, dan pengakuan tentang keberhasilan belajar diberikan untuk mendorong upaya belajar selanjutnya.

\section{Simpulan}

Dari hasil kegiatan pelatihan pembuatan terarrium dapat disimpulkan bahwa pelatihan terrarium ekosistem sebagai media pembelajaran Lab Mini dapat meningkatkan pemahaman guru tentang pengembangan pembelajaran Lab Mini di TK, pelatihan terrarium ekosistem sebagai media pembelajaran Lab Mini dapat meningkatkan kreativitas dan keterampilan guru dalam membuat media pembelajaran lab mini berupa terrarium ekosistem.

\section{Acknowledgements}

Ucapan terima kasih diucapkan kepada Kemristekdikti yang telah memberikan dana bantuan penelitian pada progam pengabdian masyarakat ini dan juga terima kasih kepada LPPM UNWAHA yang telah mendukung dan membimbing program ini.

\section{Daftar Pustaka}

Biggs, Alton., Hagins, Whitney Crispen., Kapicka, Chris., Lundgren, Linda., Rillero, Petter., Tallman, Kathleen G., and Zike, Dinah. 2004. Biology The Dinamic of Live. Cambridge:The McGraw-Hill Companies, Inc.

Biggs, Alton., Hagins, Whitney Crispen., Kapicka, Chris., Lundgren, Linda., Rillero, Petter., Tallman, Kathleen G., and Zike, Dinah. 2008. Glencoe Science Biology. Cambridge:The McGraw-Hill Companies, Inc.

Carin, A.A. 1993. Teaching Science Through Discovery, 7th Edition : California State University, Long Beach.

Gronlund, Norman E. 1981. Constructing Achievement Test. Third Edition. Englewood Cliffs: Prentice-Hall.

Kemp.1994. Designing Effective Instructional. New York: Macmillan Collage Publisher. Nur, M. 2011. Keterampilan-keterampilan Proses Sains. Surabaya: Pusat Sains dan Matematika Sekolah UNESA

Nurhayati, Susiloarifin. 2004. Pembuatan Terarium. Gramedia Press. Jakarta

Rusmiyati. 1998. "Pengembangan Kegiatan Praktikum Melalui Peneraban Lab Mini" Tesis Magister Pendidikan yang tidak dipublikasikan. Surabaya: Program Pascasarjana Universitas Negeri Surabaya.

Slavin, R.E. 2006. Educational Psycology: Theory and Practice. Massachusett: Allyn and Bacon Publisher. 